ción" como para "directa", un posible solapamiento con el conductismo, la relación de esta propuesta con la empatía, y una serie de supuestos que, indica, deben ser debidamente problematizados para seguir avanzando.

La edición de este volumen es muy importante por diversos motivos. Es el primer libro específico sobre el tema realizado en español y se inserta en importantes discusiones sobre las investigaciones en torno a la mente en una variedad de campos que exceden la filosofia, ofreciendo un panorama interdisciplinario. Además, se trata de una perspectiva que ha sido intensamente desarrollada en nuestro país por Pérez, en conjunto con investigadores de Iberoamérica, que durante las últimas dos décadas han publicado trabajos originales sobre el tema. Podríamos leer en la dedicatoria (" $A$ los amigos, indispensables segundas personas en la vida") la clave comunitaria de este trabajo, en el cual un elenco internacional de autores se citan y referencian mutuamente y comparten un interés que excede la empatía humana para pensar comunidades más amplias. Celebro la aparición de La segunda persona y las emociones e invito a su lectura y estudio.

MARCOS TRAVAGLIA

$U B A$

\title{
Miguel Escribano Cabeza, Complejidad y dinámica en Leibniz: un vitalismo ilustrado, Granada, Universidad de Granada, 2017, 286 pp.
}

$E_{\mathrm{r}}^{\mathrm{n}}$ n el presente libro, que es el resultado de la reelaboración de su tesis doctoral, Miguel Escribano Cabezas propone una lúcida reconstrucción sistemática del pensamiento de G. W. Leibniz en torno a su filosofia natural. La misma es abordada desde los problemas metafísico-ontológicos que presenta la noción de mónada como organismo vivo, desarrollada en un fecundo y complejo diálogo entre la tradición hermético-vitalista y la ciencia moderna de su tiempo. El proyecto de reforma de la filosofía por parte de Leibniz es abordado en este trabajo haciendo hincapié en su dinámica y me- tafísica. Los dos ejes centrales de la tesis están puestos en el vitalismo y la razón simbólica leibnizianos. Como nos dice Cabezas, "el vitalismo leibniziano alcanzó su madurez en la concepción de la actividad de la mónada en términos de representación, pero cuidado, el perspectivismo leibniziano no se limita a, ni es esencialmente, la actividad de un sujeto (humano), sino que caracteriza la actividad de toda sustancia en tanto se encuentra en posesión de un cuerpo orgánico. La actividad de representación se funda en aquello que hace de un cuerpo un organismo, y esto es, en esencia, su capacidad de compren- 
der en su mismo ser orgánico un medio entorno diferenciado" (p. XII). El entorno es el mundo de percepción de la sustancia, admitiendo así una infinidad de grados representativos que se ve reflejado en la diversidad natural, la que asciende de las especies químicas hasta la aparición de la conciencia o voluntad animal y la autoconciencia del hombre. A su vez, el simbolismo leibniziano, como carácter fundamental de la actividad representativa del ser orgánico de la sustancia, es tratado desde el plano ontológico, diferenciándose de la clásica lectura que hace de la semiología leibniziana una parte de su lógica o epistemología.

En el primer capítulo, "Metafísica y combinatoria en los primeros escritos", se aborda uno de los primeros problemas que interesaron profundamente a Leibniz, que fue el de la individuación y la consistencia de los cuerpos. Leibniz defiende en sus primeros escritos una propuesta mecanicista de raíz hobbesiana y gassendiana, la cual, con el tiempo, derivará en un atomismo metafísico no corpuscular, a saber, la monadología. La divisibilidad de la materia al infinito y la necesidad de un principio que dé razón de la unidad de la multiplicidad de los elementos que componen todo cuerpo fuerzan la necesidad de aceptar y pensar en la existencia de unidades metafisicas que subyacen al mundo fenoménico. Se destacan aquí las primeras discrepancias del joven Leibniz con el mecanicismo cartesiano de su tiempo, al entrever que este no logra dar cuenta de la cohesión y orden de los cuerpos.

El segundo capítulo, "La filosofía de la naturaleza y la concepción de la sustancia del joven Leibniz", presenta la teoría de la complexión leibniziana de los cuerpos desarrollada en la Nueva Física para superar las contradicciones del mecanicismo. Leibniz desarrolla allí la noción de que el principio universal de todas las cosas es la circulación del éter que, como un fluido, atraviesa todos los cuerpos otorgándoles su cohesión y posibilitando a su vez la transmisión de la luz, el sonido y el calor. La fuerza que anima y organiza los cuerpos proviene de este principio universal que genera los fenómenos de la gravedad y elasticidad, penetrando en la materia y otorgándole una forma esférica a las partículas más básicas, que Leibniz denominará "burbujas". A su vez, se trata el esquematismo de la Micrografía de Hooke y su concepto de "energía" como aporte esencial en su estudio de las diversas estructuras internas de los cuerpos materiales. Otra de las influencias del joven Leibniz, en su recuperación del concepto de forma para su concepción de la sustancia, son la neumática y la química corpuscular de Boyle, que le facilitaron la noción de reacción química como la actividad por excelencia de la naturaleza. Leibniz arribará así a una noción de forma en tanto mens como fuerza plástica y principio vital que otorga a cada individuo una estructura corpórea determinada y autorregulada.

En el tercer capítulo, "De la lógica a la dinámica: la evolución de la noción de sustancia hasta su definición como mónada", Escribano Cabeza nos embarca en el camino progresivo que trazó Leibniz en la búsqueda de una sólida definición de sustancia desde sus primeros análisis lógicos de las definiciones hasta el dinamismo interno del ser vivo. Muestra progresivamente cómo Leibniz llega a una de sus intuiciones esenciales, al concebir la actividad de la sustancia en términos de representación. El núcleo fundamental de todo pensamiento es expuesto desde la teoría de "las 
ideas", concibiéndolas como facultades, capacidades, disposiciones o hábitos naturales de la sustancia como sujeto. El pensamiento, y con él la autoconsciencia humana, es presentado en tanto forma parte de una especie más abarcativa que es la percepción. Esta, a su vez, es englobada dentro de la noción leibniziana de "expresión", la cual permite fundamentar la armonía preestablecida en los distintos órdenes del mundo natural: representación y mundo, cuerpo y alma, conocimiento (orden de los conceptos) y experiencia (orden de los fenómenos) así como la armonía entre los sujetos que conviven. La noción de sustancia en Leibniz deviene al fin plenamente vitalista al comprender toda sustancia como ser vivo que posee un dinamismo propio.

Finalmente, en "El vitalismo leibniziano: una interpretación de la Armonía Universal en perspectiva ecológica", podemos encontrar la noción de vitalismo trascendental, según la cual a cada ser vivo le corresponde un esquematismo particular por cuyo medio el individuo, el átomo metafisico, comprende su entorno físico como mundo de percepción en relación con los órganos del cuerpo. Se detallan aquí las discusiones epistolares de Leibniz con Bernoulli y De Volder sobre el entorno físico y el mundo de la percepción, los problemas de la organización de la materia y la teoría de los movimientos conspirantes, que conecta el corpularismo con su dinámica, entre otras cuestiones. Por último, el capítulo pone énfasis en la noción leibniziana de ecosistema como armonía o dependencia mutua entre las distintas especies que conviven, mostrando así cómo las intuiciones de Leibniz mantienen hoy en día una absoluta actualidad y relevancia.

Para concluir, el presente trabajo es decididamente recomendable para quienes se interesen en el pensamiento de Leibniz desde una perspectiva vitalista. No solo encontrarán un desarrollo prolijo y detallado de los problemas centrales, sino que a su vez tendrán un profundo despliegue de las influencias e ideas que el filósofo fue adoptando y criticando en el desarrollo de las mismas. De esta manera, la obra que comentamos constituye un valioso aporte para la investigación de la filosofia leibniziana, en la medida en que contribuye a la revitalización de las interpretaciones sistematizadoras del filósofo de Hannover, despegándose de las interpretaciones reduccionistas a que nos ha acostumbrado el siglo pasado y haciendo hincapié en la concepción del saber transdisciplinar que tiene por principio la ligazón universal de todas las cosas.

F. MARTÍNEZ MOSQUERA $U C A$ 